OPEN ACCESS

Edited by:

Ivan Rychlik,

Veterinary Research Institute,

Czechia

Reviewed by:

Atte Von Wright,

University of Eastern Finland, Finland

Dinesh Sriramulu,

Shres Consultancy (Life Sciences),

India

*Correspondence:

Wenhong Zhang

zhangwenhong@fudan.edu.cn

Ying Zhang

yzhang@jhsph.edu

Specialty section:

This article was submitted to Antimicrobials, Resistance and

Chemotherapy,

a section of the journa

Frontiers in Microbiology

Received: 14 July 2016 Accepted: 29 September 2016

Published: 24 October 2016

Citation:

Xu T, Han J, Zhang J, Chen J, Wu N,

Zhang $W$ and Zhang Y (2016)

Absence of Protoheme IX

Farnesyltransferase CtaB Causes Virulence Attenuation but Enhances

Pigment Production and Persister

Survival in MRSA.

Front. Microbiol. 7:1625.

doi: 10.3389/fmich.2016.01625

\section{Absence of Protoheme IX Farnesyltransferase CtaB Causes Virulence Attenuation but Enhances Pigment Production and Persister Survival in MRSA}

\author{
Tao Xu ${ }^{1}$, Jian Han ${ }^{2}$, Jia Zhang ${ }^{1}$, Jiazhen Chen ${ }^{1}$, Nan Wu ${ }^{1}$, Wenhong Zhang ${ }^{1 *}$ and \\ Ying Zhang ${ }^{1,3 *}$ \\ ${ }^{1}$ Key Laboratory of Medical Molecular Virology, Huashan Hospital, Shanghai Medical College of Fudan University, Shanghai, \\ China, ${ }^{2}$ Department of Pathogenic Biology, School of Basic Medical Sciences, Lanzhou University, Lanzhou, China, \\ ${ }^{3}$ Department of Molecular Microbiology and Immunology, Bloomberg School of Public Health, Johns Hopkins University, \\ Baltimore, MD, USA
}

The membrane protein CtaB in S. aureus is a protoheme IX farnesyltransferase involved in the synthesis of the heme containing terminal oxidases of bacterial respiratory chain. In this study, to assess the role of CtaB in S. aureus virulence, pigment production, and persister formation, we constructed a $\operatorname{ctaB}$ mutant in the methicillin-resistant Staphylococcus aureus (MRSA) strain USA500. We found that deletion of ctaB attenuated growth and virulence in mice but enhanced pigment production and formation of quinolone tolerant persister cells in stationary phase. RNA-seq analysis showed that deletion of $c t a B$ caused decreased transcription of several virulence genes including RNAlll which is consistent with its virulence attenuation. In addition, transcription of 20 ribosomal genes and 24 genes involved in amino acid biosynthesis was significantly down-regulated in the $c t a B$ knockout mutant compared with the parent strain. These findings suggest the importance of heme biosynthesis in virulence and persister formation of $S$. aureus.

Keywords: Staphylococcus aureus, heme, antibiotics, pigment, virulence, persister formation

\section{INTRODUCTION}

Staphylococcus aureus, named according to production of golden pigment, is an important human pathogen causing a variety of infection types including rampant skin and soft tissue infections, pneumonia, septicaemia, endocarditis, and central nervous system (CNS) infections. Methicillinresistant S. aureus (MRSA) is notorious for its development of antibiotic resistance and expression of multiple virulence factors. (Li et al., 2012; Carrel et al., 2015).

$S$. aureus virulence factors are multifactorial and previous studies have been mainly focused on toxins ( $\alpha$-toxin, $\gamma$-toxin, Panton-Valentine leucocidin, exfoliative toxin and phenol-soluble modulins, etc.), surface proteins (FnbP, Bap, SasX, etc.) that help bind to host cells, facilitate

Abbreviations: MRSA, methicillin resistant Staphylococcus aureus; FPP, farnesyl diphosphate; SCV, small colony variants; MIC, minimum inhibitory concentration. 
internalization and immune evasion. Staphyloxanthin, synthesized from farnesyl diphosphate (FPP) by CrtM and $\mathrm{CrtN}$, is the main component of $S$. aureus golden pigment (Liu et al., 2005). Staphyloxanthin not only plays a protecting role in bacterial fitness, but enhances virulence and survive attack by neutrophils (Clauditz et al., 2006). In addition, global regulatory systems (Agr, SaeRS, SarA, etc.) govern different aspects of physiology and expression of virulence traits, maintaining a balance between fitness and virulence.

It was in staphylococcus that persisters were first described in Bigger (1944). Persisters represent a certain portion of a bacterial culture that is genetically identical but phenotypically resistant or tolerant to antibiotics and stresses. In the model organism Escherichia coli, much research reveals the mechanisms of persister formation, including involvement of toxin-antitoxin, protein degradation, energy production and DNA repair (Zhang, 2014). However, less understood are the mechanisms of S. aureus persister formation. The portion of persisters in $S$. aureus is so high that a hypothesis was proposed that unlike E. coli, all $S$. aureus cells in stationary phase are persisters (Keren et al., 2004). Subsequently, however, Lechner et al. proved that stationary phase cultures of $S$. aureus are also a mixture of regular and persister cells (Lechner et al., 2012).

Though the key mechanisms of $S$. aureus persister formation are poorly understood, progress has been made recently. It has been reported that biofilm formation (Lewis, 2001; Resch et al., 2006) and small colony variants (SCV; Lechner et al., 2012) are two key features involving $S$. aureus persister formation, probably because the cells in biofilms and SCV cells have a different profile of gene expression, which makes them more readily to form persisters. Glycerol uptake has been reported to play a role in persister formation. Mutation in the glycerol transporter encoding gene $g l p F$ caused defective survival of $S$. aureus to ampicillin and norfloxacin (Han et al., 2014). A point mutation of the inorganic phosphate transporter gene pitA enhanced tolerance to daptomycin (Mechler et al., 2015). Mutations in purine biosynthesis genes ( $p u r B$, purF, purH, purM,) amino acid, lipid, carbohydrate metabolism, and energy production genes efflux etc. were found to cause decreased persister formation in recent transposon mutant library screens (Yee et al., 2015; Wang et al., 2015).

Heme synthesis is an important pathway in Gram positive bacteria and provide substrate to production of terminal oxidases (Mogi et al., 1994). Within vertebrates S. aureus fulfills its requirement of iron by uptaking heme-iron from transferrin or heme or hemoglobin with its several transporters including StrA, StrB, IsdA, and IsdE, etc. (Drabkin, 1951; Mazmanian et al., 2003; Liu et al., 2008; Mason and Skaar, 2009). However, in an environment without heme-iron, $S$. aureus has to synthesize heme A with a complex pathway starting from glutamate (Hammer et al., 2016). CtaB and CtaA catalyzes the last two steps of the process. $\mathrm{CtaB}$ is a heme $\mathrm{O}$ synthase (protoheme IX farnesyltransferase) and while CtaA is an integral membrane protein that converts heme O to heme A (Svensson et al., 1993; Svensson and Hederstedt, 1994; Clements et al., 1999). Heme A is essential for functional expression of the terminal oxidases. Among terminal oxidases synthesized with heme A, cytochrome aa 3 are quinol oxidases (QoxA, QoxB, etc.) and cytochrome caa 3 is a cytochrome $c$ oxidase.

Though heme synthesis mainly contributes to the pathway of synthesis of terminal oxidases that mediate bacterial respiration, it has also been reported to participate in fitness and virulence of $S$. aureus. For example, CtaA was found to be required for starvation survival and recovery from glucose starvation (Clements et al., 1999). A correlation between heme production and pigment production was reported by Lan et al., as depletion of CtaA and QoxB both enhanced pigment production, while attenuating hemolytic activity and virulence (Lan et al., 2010). However, no study has been done to address the specific effects of $c t a B$ mutation on the heme-to-respiratory chain pathway and associated phenotypic changes. In this study, we created a CtaB deletion mutant of $S$. aureus and found associations of $\mathrm{CtaB}$ with heme synthesis, pigment production as well as persister cell formation. In addition, we performed a transcriptome analysis to provide new insights into the basis of the above associations.

\section{MATERIAL AND METHODS}

\section{Bacterial Strains, Growth, and Chemical Reagents}

S. aureus USA500 (Diep et al., 2006) was used for construction of gene knockout and complementation strains. E. coli DC10B (Monk et al., 2012) was used for shuttle plasmid construction. Luria Broth medium was composed of 1\% tryptone (Oxoid), $0.5 \%$ yeast extract (Oxoid) and $0.5 \% \mathrm{NaCl}$; BM (B-Medium) was composed of $1 \%$ tryptone, $0.5 \%$ yeast extract, $0.5 \%$ glucose, $0.1 \% \mathrm{~K}_{2} \mathrm{HPO}_{4}$ and $0.5 \% \mathrm{NaCl} ; \mathrm{BM}$ and TSB (Tryptic soy broth, Oxoid) were used for $S$. aureus cultivation. Bacterial strains were inoculated in $\mathrm{BM}$, and their growth rate at $37^{\circ} \mathrm{C}$ was monitored by measuring the $\mathrm{OD}$ values at $600 \mathrm{~nm}$. Anhydrotetracycline (ATc) was used for induction of $\sec Y$ antisense RNA during gene knockout. Antibiotics were added to medium at the following concentrations: chloramphenicol, $10 \mu \mathrm{g} / \mathrm{ml}$; ampicillin, $100 \mu \mathrm{g} / \mathrm{ml}$, levofloxacin, $50 \mu \mathrm{g} / \mathrm{ml}$.

\section{Construction of Plasmids for Homologous Recombination and Complementary Strains}

We constructed plasmid pMX10 by replacing $c c d B$ element with multiple cloning sites in pKOR1 (Bae and Schneewind, 2006) and used it for construction of gene knock out strains. Primers pMX10-f and pMX10-r were mixed equally to a final concentration of $100 \mathrm{uM}$, incubated at $72^{\circ} \mathrm{C}$ for $20 \mathrm{~min}$ and slowly cooled to $4^{\circ} \mathrm{C}$. The resulting dimers were digested with BamHI and KpnI and ligated to pKOR1 backbone digested with the same restriction enzymes. To construct $\Delta c t a B$ in USA500, the upstream (us) fragment (about $1000 \mathrm{bp}$ ) at the upstream of $c t a B$ gene of USA500 strain was amplified with primer ctaB-uf and ctaB-ur, while the downstream (ds) fragment with primers ctaB$\mathrm{df}$ and ctaB-dr. The two fragments were then used as templates for fusion PCR with primer ctaB-uf and ctaB-dr. The final PCR product was digested with KpnI and MluI and then ligated into pMX10. The recombinant plasmids was transformed into 
USA500 by electroporation and mutants were selected according to the method reported by Bae et al. (Bae and Schneewind, 2006). To construct the complementation strain $\triangle c t a B:: p R B c t a B$, a fragment containing the promoter region and coding sequence of $c t a B$ gene was amplified with primers cp-ctaB-f and cp-ctaB-r. The PCR product was digested with EcoRI and BamHI and then ligated into plasmid PRB473. The resulting plasmid was transformed into the $\triangle c t a B$ mutant via electroporation. The sequences of primers are listed in Table $\mathbf{1 .}$

\section{Detection of Pigment Production and Hemolytic Activity}

To compare pigment production, USA500 and USA500 $\Delta$ ctaB were dropped onto TSA plates and USA500 $\Delta$ ctaB with pRB473 or $\mathrm{pRBctaB}$ on TSA plates with $10 \mu \mathrm{g} / \mathrm{ml}$ chloramphenicol. The plates were incubated at $37^{\circ} \mathrm{C}$ for $24 \mathrm{~h}$ and pictured. For quantitate assay of pigment production, the same strains were cultured in TSB at $37^{\circ} \mathrm{C}$ for $24 \mathrm{~h}$. For each sample, pigment was extracted with methanol and detected with a parameter (GeneSpec III, Hitachi, Japan), following a previously reported protocol (Morikawa et al., 2001). For hemolytic activity determination, the strains were analyzed by growing the strains on $5 \%$ sheep blood agar at $37^{\circ} \mathrm{C}$ for $48 \mathrm{~h}$. The result represents three independent experiments.

\section{Mouse Infection}

The mouse virulence test was performed on Balb/C mice. USA500 and the $\Delta c t a B$ mutant strains were cultured for $18 \mathrm{~h}$ and $1 \mathrm{ml}$ of the each culture was mixed with $2 \%$ Cytodex- 1 beads by 1:1. The mice were randomized into two groups ( 5 mice/group). Each mouse was challenged with $200 \mu \mathrm{l}$ bacterial mixture (each containing approximately $2 \times 10^{5}$ bacterial cells) via injection under skins on the back. After $48 \mathrm{~h}$, the mice were sacrificed and the abscess under skin was homogenized in $2 \mathrm{ml}$ PBS. The samples were diluted and plated on TSA plates at $37^{\circ} \mathrm{C}$ for $18 \mathrm{~h}$. CFU counting was performed and a Student's $t$-test was used for statistical analysis using Microsoft Excel.

Animal studies on mice were performed according to relevant national and international guidelines (the Regulations for the Administration of Affairs Concerning Experimental Animals, China) and were approved by the Institutional Animal Care and Use Committee (IACUC) of Shanghai Medical College, Fudan University (IACUC Animal Project Number: 20110630). Standard operation procedures were followed to carry out animal experiments in bio-safety level 2 labs.

\section{Susceptibility Testing}

The MIC of each antimicrobial compound was determined in triplicate by a conventional broth microdilution technique in TSB medium, following the protocol previously published (Andrews, 2001) and the CLSI guidelines. The MIC was defined as the lowest antibiotic concentration that inhibited visible bacterial growth (also according to OD600 measurements) after $24 \mathrm{~h}$ of incubation at $37^{\circ} \mathrm{C}$.
TABLE 1 | Primers used in this study.

\begin{tabular}{|c|c|c|}
\hline Primers & Sequence $5^{\prime}-3^{\prime}$ & Purpose \\
\hline pMX10-f & $\begin{array}{l}\text { GGGGTACCGCTAGCCGGCCGG } \\
\text { GGCCCACGCGTGAATTCCG }\end{array}$ & Construction of pMX10 \\
\hline $\mathrm{pM} \times 10-\mathrm{r}$ & $\begin{array}{l}\text { CGGAATTCACGCGTGGGCCCC } \\
\text { GGCCGGCTAGCGGTACCCC }\end{array}$ & \\
\hline ctaB-uf & $\begin{array}{l}\text { GGGGTACCGCTGTATAACCAT } \\
\text { AATGAACAGTACG }\end{array}$ & Construction of $\Delta c t a B$ \\
\hline ctaB-ur & $\begin{array}{l}\text { САТССТААСТТААТТААТАТС } \\
\text { ССССТССТТАААТТТТTС }\end{array}$ & \\
\hline ctaB-df & $\begin{array}{l}\text { AATTAAGGAGGGGGATTATTAAT } \\
\text { TAAGTTAGGATGAAAAATATGGG }\end{array}$ & \\
\hline ctaB-dr & $\begin{array}{l}\text { CGACGCGTAGAAGTAAGCACTT } \\
\text { TAATATCTITACC }\end{array}$ & \\
\hline$c p-c t a B-f$ & $\begin{array}{l}\text { CGGAATTCAAAAAGAACTTA } \\
\text { ATCGTAATGATIIITATTG }\end{array}$ & Construction of $\Delta c t a B:: p R B c t a B$ \\
\hline cp-ctaB-r & $\begin{array}{l}\text { CGGGATCCCTTAATTAATCT } \\
\text { AGATCAAAGTAAGTAATGAAAC }\end{array}$ & \\
\hline RThld-f & CACTGTGTCGATAATCCATT & Real-time PCR \\
\hline RThld-r & ATTAAGGAAGGAGTGATTTCAAT & \\
\hline RTesaB-f & ACTTAGCAGTACCAGCATAT & \\
\hline RTesaB-r & AATATCTCCATCAGCGATITG & \\
\hline RTset18-f & CAGAGCGATTAGCAATGATAA & \\
\hline RTset18-r & GCGTTCTTGTCTTGTGTTA & \\
\hline RThtrA-f & TGTGCTATTGAACGATAACG & \\
\hline RThtrA-r & CTTGCTCTGCTTGATAACTC & \\
\hline RTarcB2-f & TGAACCTGATGAAGTATGGA & \\
\hline RTarcB2-r & TGGAAAGATGGTAAGCAATG & \\
\hline RTsdhA2-f & CAGCAGATITAGCATTAGCA & \\
\hline RTsdhA2-r & TACGACCAACCTTATCCATT & \\
\hline RTnrdE-f & CGATGGTATGGCTATTCCTA & \\
\hline RTnrdE-r & CGATTGGCATTACAGAACTT & \\
\hline RTpyrF-f & TAGATGGCGTTGTITGTTC & \\
\hline RTpyrF-r & GTAATACGGTGTTGGTCATT & \\
\hline RTrpmC-f & TTAGAGACTTAACCACTTCAGA & \\
\hline RTrpmC-r & CTाTCACGAGCAACAGTाT & \\
\hline RTagrD-f & AACATTGGTAACATCGCAG & \\
\hline RTagrD-r & GTGTTAATTCTITGGTACTTCA & \\
\hline RTdltA-f & TGGTTCATTCAAGGTCGTA & \\
\hline RTdltA-r & GCATTGTCCGTAACTTCAG & \\
\hline$R \operatorname{Trs} 1-f$ & GTGCTACAATGGACAATACAA & \\
\hline$R \operatorname{Trs} 1-r$ & ACTACAATCCGAACTGAGAA & \\
\hline
\end{tabular}

\section{Persister Assay}

To determine the number of persister cells in exponential phase, cells were grown overnight in $4 \mathrm{ml}$ and were inoculated to $10 \mathrm{ml}$ of fresh medium to an initial OD600 of 0.05. Cultures were shaken for 1.5-2 h (for normally growing cells), until an OD600 of approximately 0.5 was reached. To determine the number of persister cells in stationary phase, overnight cultures (16 or $24 \mathrm{~h}$ ) were used without dilution.

For heat stress assay, stationary phase cultures were incubated at $57^{\circ} \mathrm{C}$ for up to $3 \mathrm{~h}$. For oxidative stress assay, stationary phase cultures were diluted by $1: 100$ in TSB that contained $50 \mathrm{mM}$ hydrogen peroxide $\left(\mathrm{H}_{2} \mathrm{O}_{2}\right)$ for $4 \mathrm{~h}$. 
For starvation stress assay, stationary phase cultures were centrifuged, washed and resuspended in $3 \% \mathrm{NaCl}$. The survival of bacteria was determined by CFU counting at each hour. All stress assays were conducted using at least three biological replicates.

For antibiotic exposure, $2 \mathrm{ml}$ of the overnight or the exponential phase cultures was transferred to $14 \mathrm{ml}$ culture tubes (Greiner), antimicrobials were added at 100-fold MIC as indicated and the cultures were shaken for $12 \mathrm{~h}$, or for 7 days during long-term experiments. For CFU determination, $100 \mu \mathrm{l}$ was taken before and during antimicrobial challenge on an hourly basis during the first $8 \mathrm{~h}$ and after $24 \mathrm{~h}$, or after $1,2,3$, 5, 6 days during long-term experiments. Cells were washed in PBS and spotted as $10 \mu \mathrm{l}$ aliquots of serial dilutions onto TSA plates. Colonies were counted after incubation for $24 \mathrm{~h}$ at $37^{\circ} \mathrm{C}$. The lower limit of quantification was $100 \mathrm{CFU} / \mathrm{ml}$. All timekill experiments were conducted using at least three biological replicates.

\section{RNA Isolation, mRNA Enrichment and Sequencing}

S. aureus USA500 parent strain and $\triangle c t a B$ mutant were cultured for 6 or $24 \mathrm{~h}$ as log phase and stationary phase cultures. The cultures were divided into 3 aliquots and treated with RNAprotect (Qiagen) and frozen at $-80^{\circ} \mathrm{C}$. Total RNA was extracted from bacterial cells using the RNeasy Mini kit (Qiagen) as described (Atshan et al., 2012). The quality of RNA samples was examined with Bioanalyzer 2100 RNA-6000 Nano Kit. To remove $16 \mathrm{~S}$ and $23 \mathrm{~S}$ rRNAs, $10 \mu \mathrm{g}$ of high-quality total RNA was processed using the Ribo-Zero ${ }^{\mathrm{TM}}$ Gold Kit before precipitating with ethanol and resuspending into $25 \mu \mathrm{L}$ of nuclease-free water. The cDNA libraries with 150- to 250-bp multiplexed cDNA were generated from the enriched mRNA samples using the TruSeq Illumina kit (Illumina, San Diego, CA), following instructions from the manufacturer.

Sequencing was performed with HiSeq2500 (Illumina). The Cufflinks suite of tools were used to assess and quantify the total number of reads. With the program Cuffdiff as part of the suite, transcripts were quantified by assessing the total number of reads for the entire transcript. Briefly, reads were mapped to annotated coding sequences (CDSs) from genome of S. aureus USA300 TCH1516 strain since USA500 is the progenitor of USA300. The samples to be compared were evaluated for variance and tested for differential expression. Reads' $P$-values were determined, and significance was assessed by conducting Benjamini-Hochberg correction for multiple testing. The transcript sequencing data were submitted to the NCBI Sequence Read Archive, available for access under a RUN number RSS3919726.

\section{Quantitative Real-Time PCR}

For quantitative Real-time PCR, the same RNA samples were taken from that used for RNA-seq. After reverse transcription with cDNA Synthesis Kit (Bio-Rad Laboratories, Hercules, CA), qRT-PCR was performed using SYBR Green PCR reagents (Takara Biotechnology) to determine the relative expression levels of the target genes with gene-specific primers listed in Table 1. The housekeeping gene $r r s 1$ (16s RNA) was used as an endogenous control. All qRT-PCR experiments were carried out in triplicate with independent RNA samples and the $2^{-\Delta \Delta C T}$ method was performed for analysis of relative gene expression data (Livak and Schmittgen, 2001).

\section{Statistics}

The significance of experimental differences in pigment production, hemolytic activity, survival in vivo and persister assay was evaluated by unpaired Student's $t$-test.

\section{RESULTS}

\section{Construction and Properties of the S. aureus ctaB Deletion mutant $\Delta$ ctaB}

To investigate the functions of $\mathrm{CtaB}$, we constructed a $\operatorname{ctaB}$ deletion mutant, $\triangle c t a B$, via homologous recombination, as well as made a complemented strain $\triangle c t a B:: p R B c t a B$ by inserting $c t a B$ with its own promoter into plasmid pRB473. When grown in TSB, the $\triangle c t a B$ mutant showed a slight growth defect, compared with the parent strain USA500 (Figure 1A). The $\triangle c t a B$ mutant displayed enhanced golden pigment production when grown on TSA for $24 \mathrm{~h}$ compared with the control strain (Figure 1B), and complementation of the $\triangle c t a B$ mutant reduced pigment production to normal levels (Figure 1B). Quantification of pigment production by extracting carotenoid products confirmed that $\mathrm{CtaB}$ depletion afforded enhanced pigmentation than USA500 strain (Figure 1C).

\section{CtaB Affects Hemolytic Activity and Survival In vivo}

Hemolytic ability is an important aspect of $S$. aureus virulence (Wang and Muir, 2016). We analyzed the level of bacterial growth and hemolysis of the $\triangle c t a B$ mutant on sheep blood agar plates. While all strains showed similar sized colonies, deletion of $c t a B$ generated a strain with reduced hemolytic activity, which could be restored by complementation of the $\triangle c t a B$ mutant with the wild type $c t a B$ gene (Figure 2A).

Having observed that the $\triangle c t a B$ mutant enhanced pigment production but reduced hemolytic activity, we wondered whether $\triangle c t a B$ mutant would affect virulence in vivo. Skin is one of the most frequently targeted sites for S. aureus infection (Liu, 2009). To determine whether $\mathrm{CtaB}$ is associated with virulence during $S$. aureus infection, we compared the $\triangle c t a B$ mutant and the parent strain in a mouse model of skin abscess. Colony counting of bacteria from mouse skin lesions showed that inactivation of $c t a B$ attenuated bacterial survival in vivo. After $24 \mathrm{~h}$ of infection, the CFU counting of USA500 increased from $6.18 \pm 0.46 \mathrm{E}+6$ to $6.79 \pm 1.02 \mathrm{E}+6$. Within contrast, the $\triangle c t a B$ mutant survived less well with a decrease of CFU, from $4.74 \pm 0.57 \mathrm{E}+6$ to $2.96 \pm$ $1.3 \mathrm{E}+6$. (Figure 2B).

\section{CtaB is Involved in Persister Cell Formation under Stress and Antibiotic Treatment}

To determine if $\mathrm{CtaB}$ is involved in persister formation or survival, we subjected stationary cultures of USA500, $\Delta c t a B$ and $\triangle c t a B:: p R B c t a B$ under stress conditions including heat, oxidative stress, and starvation. The $\mathrm{CtaB}$ mutation attenuated the ability of 


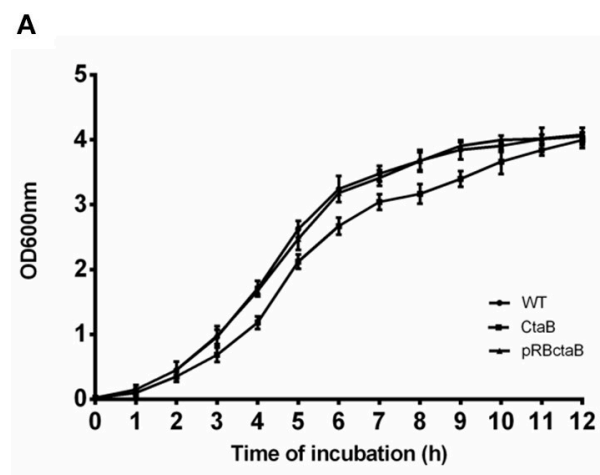

B

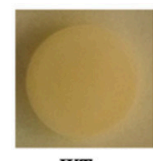

$W T$

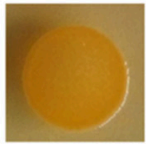

$c t a B$

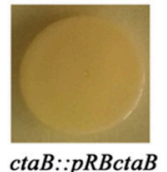

C

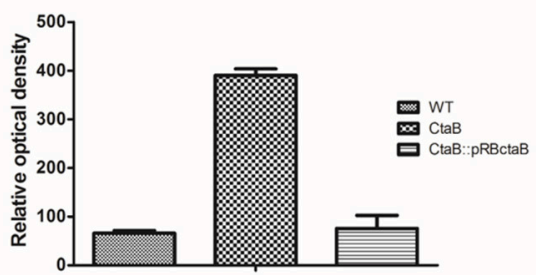

FIGURE 1 | (A) Comparison of the growth rate of USA500 and the $\triangle$ ctaB mutant. A saturated overnight culture of each strain was inoculated in a 12 ml tube and cultured at $37^{\circ} \mathrm{C}$. Cultures were monitored by measuring absorption at OD600 each hour. (B) Pigmentation display of $\mathrm{S}$. aureus strains grown on TSA plates at $37^{\circ} \mathrm{C}$ for $24 \mathrm{~h}$. (C) Measurement of the golden pigment of different strains by methanol extraction. The relative optical density units were detected at 465 nm and normalized to the USA500 strain, which was set at 100. Results are means with standard error (error bars) of three independent experiments.
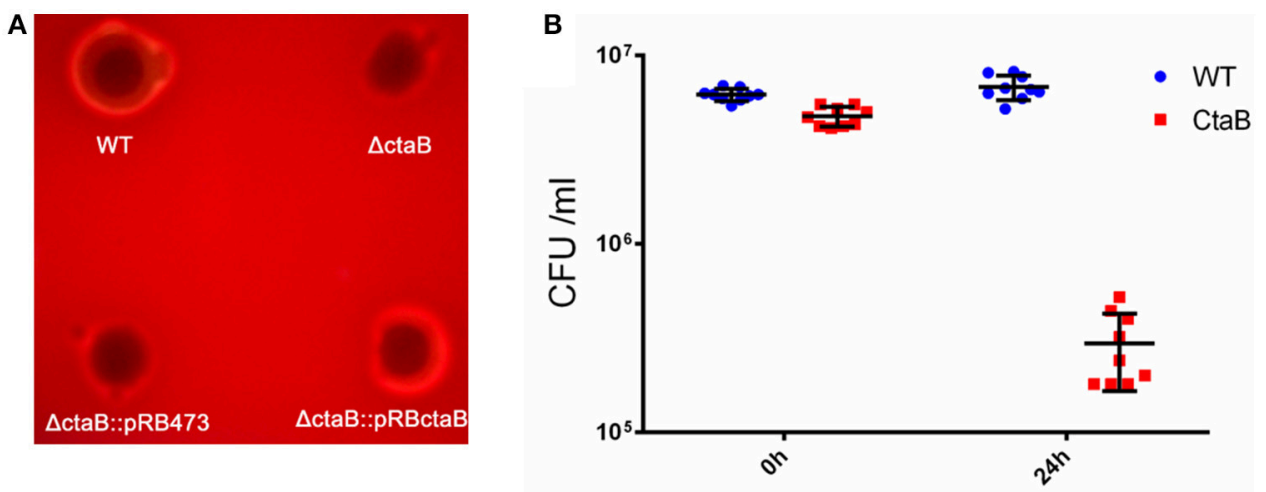

Time of infection( $\mathrm{h}$ )

FIGURE 2 | (A) Hemolytic activity assay. Overnight cultures of USA500, $\Delta$ ctaB mutant and complemented strains were spotted (20 $\mu$ I) on sheep blood agar plates and grown at $37^{\circ} \mathrm{C}$ for $24 \mathrm{~h}$. The result is representative of triplicate experiments. (B) Survival of $S$. aureus strains in a Balb/C challenged by subcutaneous injection. Comparison of CFU counts was performed using the Student's t-test. Results are means with standard error (errors bars).

S. aureus to survive starvation in $3 \% \mathrm{NaCl}$, which provides similar osmotic pressure as TSB, and the impact was reversed by gene complementation (Figure 3A). However, CtaB knockout did not affect survival of $S$. aureus under treatment with heat or $\mathrm{H}_{2} \mathrm{O}_{2}$ (data not shown).

Before persister assay, we measured the antibiotic sensitivity of $c t a B$ mutant and found no difference in MIC tests for multiple antibiotics (data not shown). Challenging the stationary phase cultures of USA500, $\triangle c t a B$ and $\Delta c t a B:: p R B c t a B$ with 100 $\mathrm{X}$ MIC ciprofloxacin or levofloxacin yielded disparate killing curves. As shown in Figures $(3 \mathrm{~B}, \mathrm{C})$, the surviving ratios of $\triangle c t a B$ were similar with that of USA500 in the first 3 days, but became higher than the control strain in day four and day five. Meanwhile, complementation with plasmid pRBctaB but not pRB473 partially reversed the augmentation of persister formation caused by deletion of $c t a B$ in the last 2 days of treatment. We also tested other antibiotics such as vancomycin, rifampicin, streptomycin, tobramycin, and gentamycin at $100 \mathrm{X}$ MIC concentration but found no significant difference in persister formation between the $\triangle c t a B$ mutant and the parent strain from either exponential phase or stationary phase (data not shown).

\section{RNA-seq Analysis of the $\triangle c t a B$ Mutant Compared with its Parent Strain USA500}

The above results indicate an intriguing and paradoxical role of $\mathrm{CtaB}$ in persistence and virulence of $S$. aureus, as its deletion attenuated virulence and survival in $3 \% \mathrm{NaCl}$ while increasing persister numbers for quinolone antibiotics. To gain insights into the role of $\mathrm{CtaB}$ in altered $S$. aureus virulence and persistence, we performed RNA-seq analysis of USA500 and $\triangle c t a B$ mutant grown for $6 \mathrm{~h}$ (log phase) or $24 \mathrm{~h}$ (stationary phase) in TSB medium. Based on the results of read counts of all annotated 


\section{A}
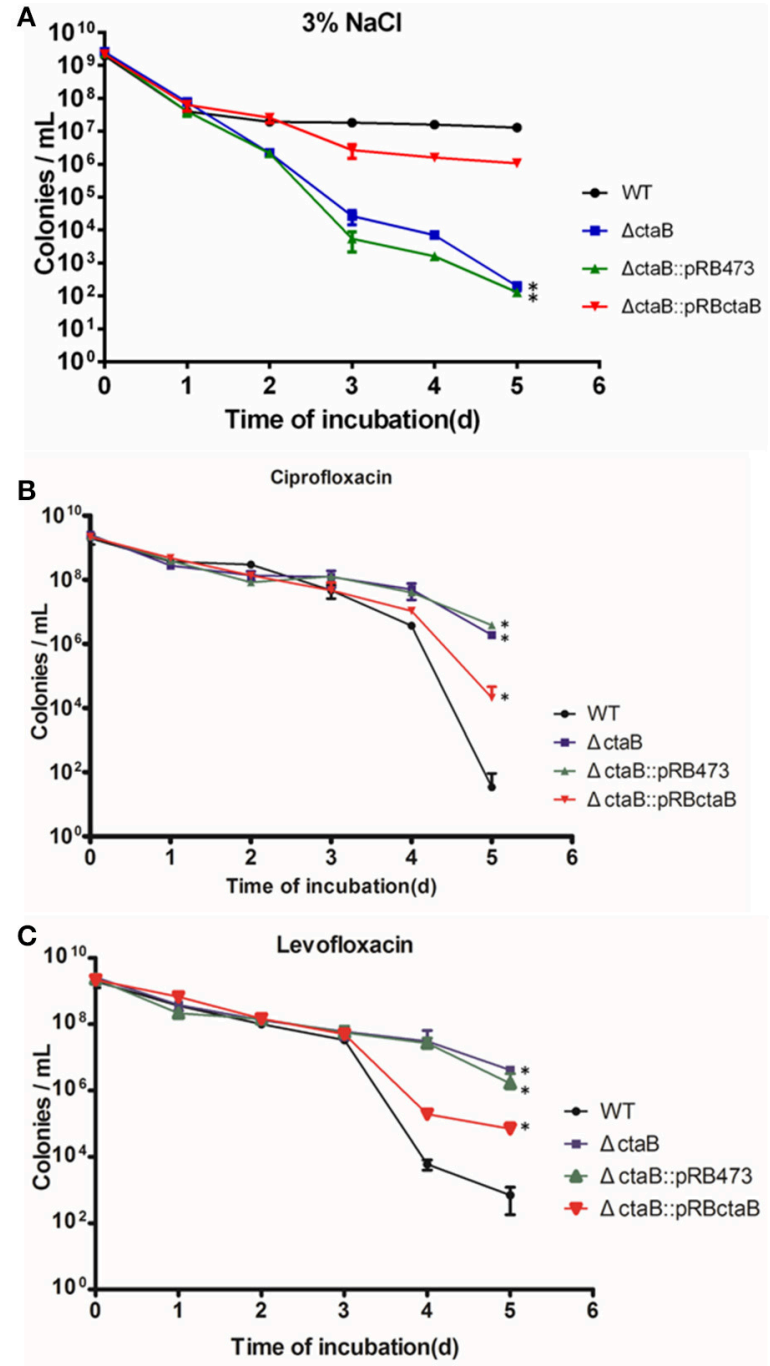

FIGURE 3 | Time dependent killing of S. aureus stationary phase bacteria. (A) Effects of starvation ( $3 \% \mathrm{NaCl}$ ) on survival kinetics of $\mathrm{S}$. aureus USA500, $\triangle$ ctaB mutant and complemented strain. Results are representative of three independent experiments. (B,C) Persister assay with antibiotics. Strains were treated with (B) $20 \mu \mathrm{g} / \mathrm{ml}$ ciprofloxacin or (C) $50 \mu \mathrm{g} / \mathrm{ml}$ levofloxacin for 6 days. The limit of detection was $100 \mathrm{CFU} / \mathrm{ml}$ throughout all killing experiments. Results are representative of three independent experiments.

genes, a total of 4 RNA-seq samples were clustered without supervision (Figure 4). The results indicated that the effect of $\mathrm{CtaB}$ knockout on the bacterial transcriptome at $24 \mathrm{~h}$ were more apparent than that at $6 \mathrm{~h}$ (Figures 5A,B).

In log phase cultures, we found 18 genes with significant changes in transcription (cutoff $>2$-fold) and $p$-values less than 0.05 between $\triangle c t a B$ mutant and the parent strain (Table 2). Most strikingly, the virulence gene hld was significantly down regulated $(0.35, p=8.47 \mathrm{E}-05)$ in the $\Delta c t a B$ mutant. In $S$. aureus, gene hld is located inside the coding sequence for small regulatory RNA RNAIII which regulates the expression of many $S$. aureus genes encoding exoproteins and cell-wall-associated

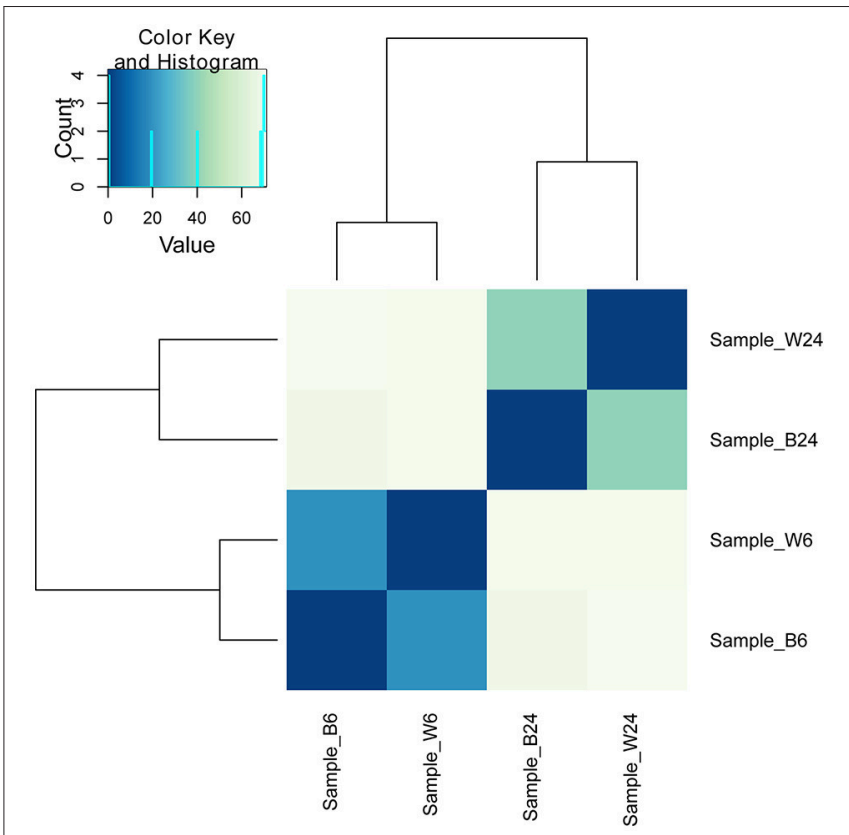

FIGURE 4 | Clustering of 4 RNA-seq samples. Sample_W6, USA500 grown to $6 \mathrm{~h}$; Sample_B6, USA500 $\Delta$ ctaB grown to $6 \mathrm{~h}$; Sample_W24, USA500 grown to $24 \mathrm{~h}$; Sample_B24, USA500 $\Delta$ ctaB grown to $24 \mathrm{~h}$. Heatmap shows the Euclidean distances between the samples as calculated from the variance-stabilizing transformation of the count data.

proteins. The data indicated that deletion of $\mathrm{CtaB}$ could attenuate expression of various virulence genes regulated by RNAIII in log phase. Interestingly, $\mathrm{CtaB}$ deletion did not affect expression of the Agr system (encoded by $\operatorname{agr} B, \operatorname{agr} D, \operatorname{agr} C$, and $\operatorname{agr} A$ ), which is the well-known upstream regulator of RNAIII and a virulence factor. The virulence gene esaB (Burts et al., 2008; Anderson et al., 2011)was also down regulated. Meanwhile, the virulence genes set18 and set 19 were up regulated in the $\triangle \operatorname{cta} B$ mutant. Two hemin ABC transporter super family genes $h t r B$ and $h t r A$ were significantly up regulated, as a consequence of lack of heme caused by deletion of CtaB (Table 2).

For the transcripts at $24 \mathrm{~h}, 119$ genes showed significant changes between $\triangle c t a B$ mutant and the parent strain (Table 3), indicating that $\mathrm{CtaB}$ has a major impact on stationary phase $S$. aureus. The proposed pathways that these genes participate in were analyzed (Figure 6). Nineteen genes encoding ribosome proteins were strongly down regulated, as well as nine genes involved in biosynthesis of Aminoacyl-tRNA. Genes involved in arginine, proline, cysteine, methionine, glycine, serine, threonine, lysine, phenylalanine, tyrosine, tryptophan, valine, leucine, and isoleucine were down regulated in the $\mathrm{CtaB}$ mutant. Expression of several ABC transporters was also up regulated, but other transporters such as OppA1, OppB3, OppC1, OppD1, and OppF1, were down regulated. Twenty two genes that encode factors for amino acid metabolism showed difference in expression. Expression of two genes ( $\operatorname{arcB} 2$ and $\operatorname{arcC1}$ ) involved in arginine metabolism was up regulated while the others were down regulated. The deletion of $\mathrm{CtaB}$ also down regulated genes from pathways involved in purine 

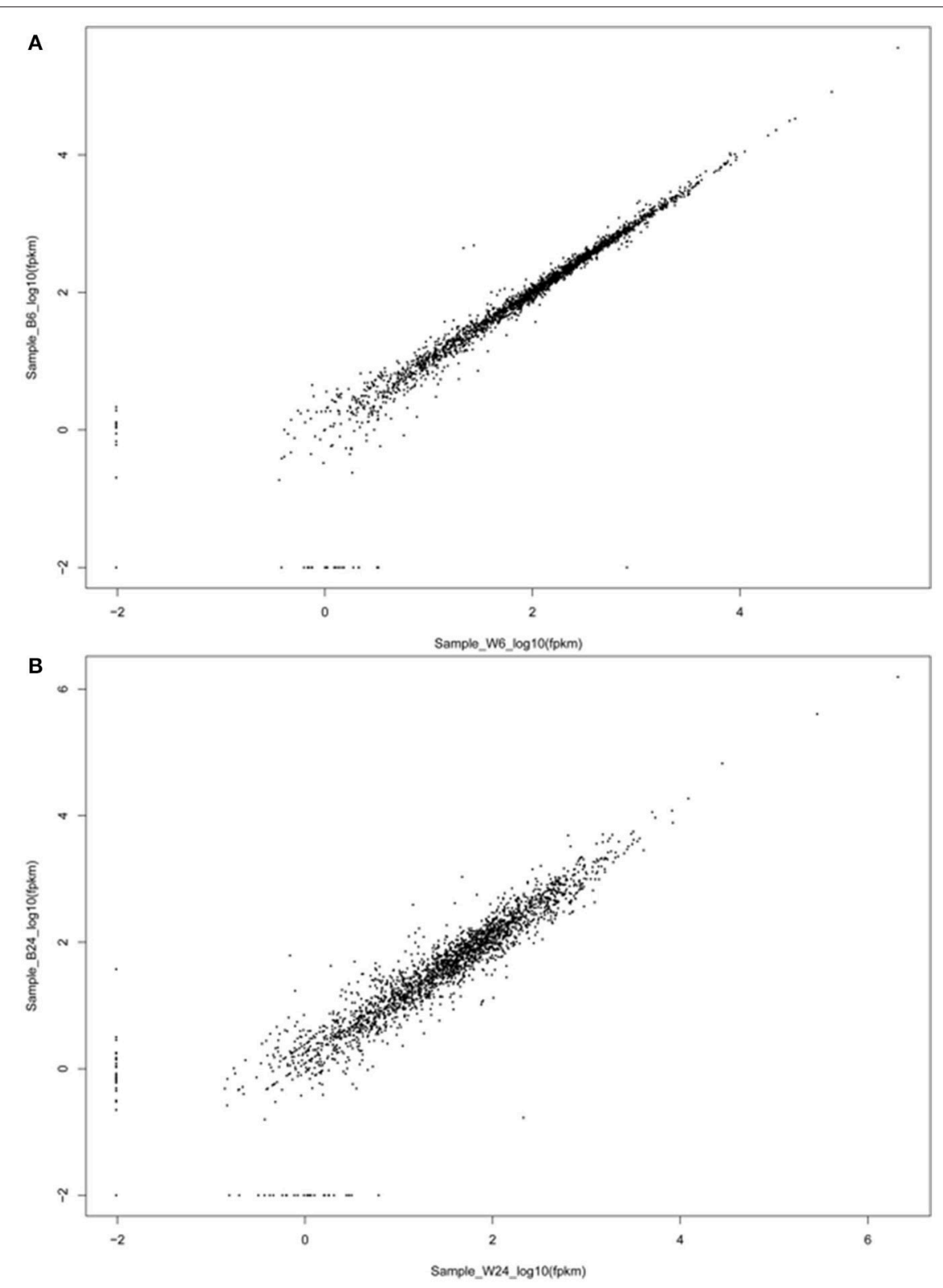

FIGURE 5 | Scatter plot of the expression levels of pairs of adjacent genes. The expression levels of two genes located within the same transcript of log phase bacteria (A) and stationary phase bacteria (B) are plotted in $\log _{10}$ scale.

metabolism, pyrimidine metabolism, and fatty acid biosynthesis. Though out of 17 genes associated with $S$. aureus infection 12 were up regulated, genes in the $d l t$ operon $(\operatorname{dlt} A, \operatorname{dlt} B, \operatorname{dlt} C$, and $d l t D$ ) were significantly down regulated (Collins et al., 2002). The CtaB deletion also induced expression of genes of five two-component systems, including PhoPR, LgrAB, SaeRS, and LytSR, indicating that these systems might play a role when $S$. aureus is confronted with lack of heme biosynthesis (Table 3).

Quantitative Real-time PCR was performed to validate the RNA-seq results. Genes were chosen from the list of genes with significant changes of transcription, favoring those associated with virulence and protein production but had a $p$-value $<0.05$. All showed similar fold change with those from the RNA-seq results (Figure 7).

\section{DISCUSSION}

The aim of this study is to address the role of $\mathrm{CtaB}$ in pigment production, virulence and persister formation in $S$. aureus. We found that deletion of $c t a B$ attenuated survival under starvation and virulence in mice but had enhanced pigment production and formation of quinolone tolerant persister cells. Our study is the first to report the complex relationship 
TABLE 2 | List of genes differentially expressed in USA500 and $\Delta \mathrm{ctaB}$ grown to $6 \mathrm{~h}$.

\begin{tabular}{|c|c|c|c|c|}
\hline Gene & Gene symbol & $\log _{2}$ fold change & $p$-value & Description \\
\hline USA300HOU_RS14135 & & -2.04 & 4.4E-05 & Hypothetical protein \\
\hline USA300HOU_RS09600 & & -1.96 & 1.1E-03 & Hypothetical protein \\
\hline USA300HOU_RS10850 & & -1.83 & $1.2 \mathrm{E}-02$ & Hypothetical bacteriophage protein \\
\hline USA300HOU_RS 10955 & hld & -1.53 & 8.5E-05 & Delta-hemolysin \\
\hline USA300HOU_RS 03725 & & -1.42 & 9.0E-04 & Hypothetical membrane protein \\
\hline USA300HOU_RS 05170 & & -1.24 & 1.9E-03 & Hypothetical protein \\
\hline USA300HOU_RS 04240 & & -1.07 & 3.7E-02 & Hypothetical protein \\
\hline USA300HOU_RS 10770 & & 1.02 & $1.8 \mathrm{E}-02$ & Hypothetical protein \\
\hline USA300HOU_RS 09400 & ribD & 1.06 & 9.6E-07 & Diaminohydroxyphosphoribosylaminopyrimidine deaminase \\
\hline USA300HOU_RS 12385 & ure $B$ & 1.09 & 1.3E-02 & Urease beta subunit \\
\hline USA300HOU_RS 09390 & ribA & 1.13 & 2.0E-07 & Bifunctional 3,4-dihydroxy-2-butanone-4-phosphate synthase/GTP cyclohydrolase II \\
\hline USA300HOU_RS 10800 & & 1.17 & $2.8 \mathrm{E}-03$ & Hypothetical bacteriophage protein \\
\hline USA300HOU_RS 09395 & ribB & 1.32 & $3.5 \mathrm{E}-08$ & Riboflavin synthase alpha subunit \\
\hline USA300HOU_RS 13155 & & 1.32 & 1.6E-02 & ABC superfamily ATP binding cassette transporter, ABC/membrane protein \\
\hline USA300HOU_RS 06710 & & 1.32 & 2.3E-02 & ABC superfamily ATP binding cassette transporter, membrane protein \\
\hline USA300HOU_RS 03970 & & 1.39 & 4.5E-07 & Iron (Fe+3) ABC superfamily ATP binding cassette transporter, membrane protein \\
\hline USA300HOU_RS 12770 & htrB & 4.14 & $1.2 \mathrm{E}-51$ & Hemin ABC superfamily ATP binding cassette transporter, ABC protein \\
\hline USA300HOU_RS 12775 & htrA & 4.34 & 1.6E-55 & Hemin ABC superfamily ATP binding cassette transporter, membrane protein \\
\hline
\end{tabular}

between heme production, persister formation, and virulence in S. aureus.

We have shown that $\mathrm{CtaB}$ depletion barely affected growth in rich medium (TSB), but caused faster death under starvation stress (Figure 3A). The result echoes the finding by Clements et al., as CtaA mutation caused growth defect in glucoselimiting chemically defined medium (Clements et al., 1999). Heme production is a key step for cellular aerobic respiration and energy conversion, providing resources for synthesis of heme A-containing terminal oxidases (Svensson and Hederstedt, 1994; Hederstedt et al., 2005). The changes in the respiratory chain by mutation of $\mathrm{CtaB}$ could account for the defects. Meanwhile, it is more difficult to explain the enhanced pigment production caused by $\mathrm{CtaB}$ depletion. The production of staphyloxanthin, the main pigment of Staphylococci, is mediated by factors encoded by crtOPQMN, using FPP as the substrate (Wieland et al., 1994; Pelz et al., 2005). Regulators such as $r s b U V W$-sigB are known to regulate expression of pigment genes in S. aureus (Kullik et al., 1998; Giachino et al., 2001). In previous reports, suppression of genes from metabolic pathways (purine biosynthesis, the TCA cycle and oxidative phosphorylation) has also been found to affect pigment production (Lan et al., 2010). We detected the expression of pigment associated genes and found that $\mathrm{CtaB}$ deletion did not affect expression of $r s b U V W$-sigB, fliA (sigB) or crtOPQMN, while expression of cit $Z$ in $\triangle c t a B$ mutant was down regulated (0.45) while qoxB was induced (2.09), and the other metabolic genes were not affected (Table 4). FPP is a key intermediate in mevalonate pathway that serves as a substrate of several pathways including synthesis of heme A and staphyloxanthin (Szkopinska and Plochocka, 2005). Since $\mathrm{CtaB}$ deletion did not affect pigment production by altering expression of the currently known genes of pigment production pathway, the possibility is worth considering that the absence of competition by heme A production pathway leaves more FPP to staphyloxanthin synthesis pathway, thus enhancing pigment production provided.

From the RNA-seq data, we show the down regulation of multiple virulence genes was caused by $\mathrm{CtaB}$ depletion. Despite the depression of global regulatory RNA RNAIII and several classic virulence factors (EsaB, EsaC, EsXB, etc.), DltA-D and most of the amino acid $\mathrm{ABC}$ transporters were down regulated. The four proteins (DltA-D) incorporate D-alanine into cell wall polymers during teichoic acid synthesis (Reichmann et al., 2013) and their inactivation has been shown to impact the defense of $S$. aureus against antimicrobial agents (Peschel et al., 1999). Expression of many amino acid transporter genes (oppA1, $o p p C 1, o p p D 1$, and $o p p F 1$ ) were found down regulated in the $\mathrm{CtaB}$ knockout strain. These ABC transporters not only function by obtaining nutrients, but play important roles in adherence and processing of secreting toxins (Podbielski et al., 1996). They also showed up frequently in screening of virulence genes of $S$. aureus with transposon libraries in different animal models (Mei et al., 1997; Coulter et al., 1998; Bae et al., 2004).

Pigment production has been found to enhance fitness and virulence and help the bacteria cope with oxidative stress (Clauditz et al., 2006). However, our results seem to contradict this finding of association of pigment production and virulence as we see enhanced pigment production of $\mathrm{CtaB}$ mutant but less virulence. Nevertheless, $\mathrm{CtaB}$ deletion had multiple effects on $S$. aureus, despite enhanced pigment production, it caused attenuated hemolytic activity and survival in animal model. It is likely the virulence attenuation of $\mathrm{CtaB}$ mutant is combined effect of more important attenuated hemolytic activity over the increased pigment production such that the net outcome is 
TABLE 3 | List of genes differentially expressed in USA500 and $\Delta$ ctaB grown to $24 \mathrm{~h}$.

\begin{tabular}{|c|c|c|c|c|}
\hline Gene & Gene symbol & $\log _{2}$ fold change & $p$-value & Description \\
\hline USA300HOU_RS01190 & & -3.37 & 3.36E-06 & Acetyl-CoA C-acetyltransferase \\
\hline USA300HOU_RS01195 & & -3.30 & 7.44E-06 & 3-hydroxyacyl-CoA dehydrogenase \\
\hline USA300HOU_RS01205 & & -3.16 & 1.08E-05 & Long-chain-fatty-acid-CoA ligase \\
\hline USA300HOU_RS02265 & cobW1 & -2.78 & 6.77E-04 & Cobalamin (vitamin B12) biosynthesis protein \\
\hline USA300HOU_RS02055 & xprT & -2.66 & 1.47E-03 & Xanthine phosphoribosyltransferase \\
\hline USA300HOU_RS12265 & & -2.57 & 2.28E-03 & Hypothetical protein \\
\hline USA300HOU_RS14500 & lip & -2.16 & 2.42E-03 & Triacylglycerol lipase \\
\hline USA300HOU_RS02060 & pbux & -2.16 & 3.25E-03 & NCS2 family nucleobase:cation symporter-2 \\
\hline USA300HOU_RS05895 & & -2.14 & 1.26E-02 & Antibacterial protein \\
\hline USA300HOU_RS00655 & & -2.03 & 3.65E-02 & Hypothetical membrane protein \\
\hline USA300HOU_RS01875 & & -2.01 & 4.74E-02 & Hypothetical protein \\
\hline USA300HOU_RS04875 & $\mathrm{fabH} 1$ & -1.95 & 4.11E-03 & 3-oxoacyl-[acyl-carrier-protein] synthase \\
\hline USA300HOU_RS02840 & rplL1 & -1.94 & 5.40E-03 & Ribosomal protein L7/L12 \\
\hline USA300HOU_RS12130 & $r p s Q$ & -1.93 & 5.02E-03 & Ribosomal protein S17 \\
\hline USA300HOU_RS04900 & oppD1 & -1.91 & 4.92E-03 & Oligopeptide ABC superfamily ATP binding cassette transporter, ABC protein \\
\hline USA300HOU_RS11060 & $i / v D$ & -1.89 & 1.79E-02 & Dihydroxy-acid dehydratase \\
\hline USA300HOU_RS07110 & dapB & -1.84 & 1.91E-02 & Dihydrodipicolinate reductase \\
\hline USA300HOU_RS13735 & & -1.82 & 1.46E-02 & Transcriptional regulator \\
\hline USA300HOU_RS08760 & $r p / U$ & -1.79 & 1.10E-02 & Ribosomal protein L21 \\
\hline USA300HOU_RS02835 & rplJ & -1.65 & 1.75E-02 & Ribosomal protein $L 10$ \\
\hline USA300HOU_RS02375 & gltB1 & -1.63 & 2.23E-02 & Glutamate synthase (NADPH), large subunit \\
\hline USA300HOU_RS06050 & pyrF & -1.62 & 3.08E-02 & Orotidine-5'-phosphate decarboxylase \\
\hline USA300HOU_RSO4905 & oppF1 & -1.58 & 1.92E-02 & Oligopeptide ABC superfamily ATP binding cassette transporter, ABC protein \\
\hline USA300HOU_RS01935 & rpsF & -1.56 & 2.29E-02 & Ribosomal protein S6 \\
\hline USA300HOU_RS04620 & $d l t A$ & -1.55 & 2.45E-02 & Long-chain-fatty-acid-CoA ligase \\
\hline USA300HOU_RS07105 & $\operatorname{dap} A$ & -1.52 & 4.99E-02 & dihydrodipicolinate synthase \\
\hline USA300HOU_RS04635 & $d / t D$ & -1.51 & 3.00E-02 & D-alanine transfer protein DltD \\
\hline USA300HOU_RS07190 & & -1.51 & 4.86E-02 & Nitric-oxide reductase \\
\hline USA300HOU_RS12610 & hutl & -1.50 & 2.99E-02 & Imidazolonepropionase \\
\hline USA300HOU_RSO2380 & $g / t D$ & -1.50 & 4.97E-02 & Glutamate synthase (NADPH) small subunit \\
\hline USA300HOU_RS05945 & murD & -1.50 & 2.66E-02 & UDP-N-acetylmuramoylalanine-D-glutamate ligase \\
\hline USA300HOU_RS08555 & & -1.49 & 2.77E-02 & Biotin carboxylase \\
\hline USA300HOU_RS12615 & hutU & -1.49 & 3.30E-02 & Urocanate hydratase \\
\hline USA300HOU_RS13410 & & -1.47 & 3.09E-02 & Possible decarboxylase \\
\hline USA300HOU_RS12085 & rpmD & -1.46 & 2.95E-02 & Ribosomal protein L30 \\
\hline USA300HOU_RS11770 & & -1.46 & 3.46E-02 & Hypothetical membrane protein \\
\hline USA300HOU_RS06545 & glpK & -1.45 & 3.79E-02 & Glycerol kinase \\
\hline
\end{tabular}


TABLE 3 | Continued

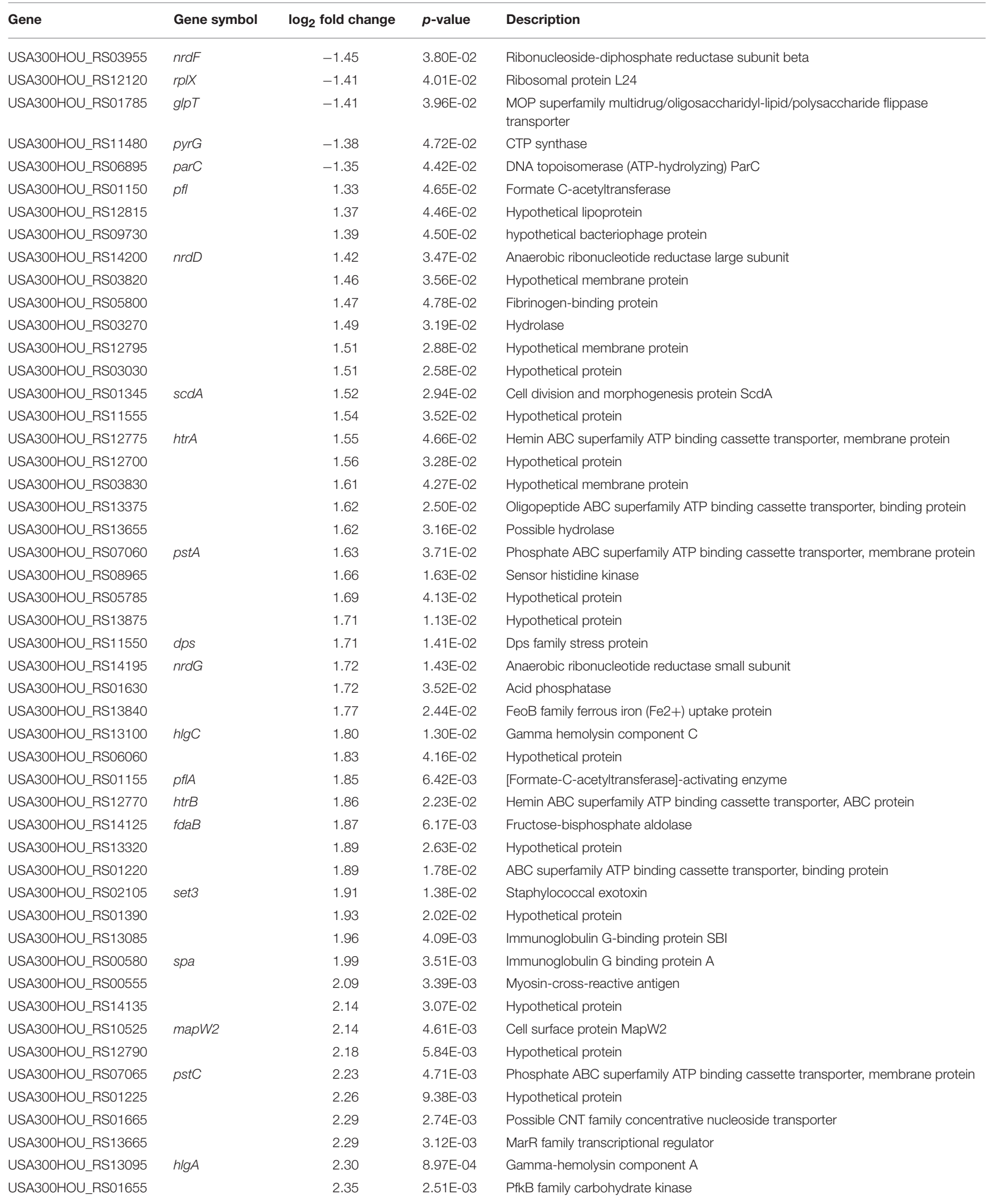


TABLE 3 | Continued

\begin{tabular}{|c|c|c|c|c|}
\hline Gene & Gene symbol & $\log _{2}$ fold change & $p$-value & Description \\
\hline USA30OHOU_RS03725 & & 2.41 & 1.29E-02 & Hypothetical membrane protein \\
\hline USA30OHOU_RS04290 & nuc & 2.48 & $3.60 \mathrm{E}-03$ & Micrococcal nuclease \\
\hline USA300HOU_RS13635 & & 2.50 & 2.35E-03 & ABC superfamily ATP binding cassette transporter, membrane protein \\
\hline USA300HOU_RS13830 & $c / p$ & 2.51 & 2.93E-04 & S14 family endopeptidase Clp \\
\hline USA300HOU_RS13660 & & 2.53 & $1.74 \mathrm{E}-03$ & Possible lactoylglutatione lyase \\
\hline USA300HOU_RS01660 & & 2.62 & $9.10 \mathrm{E}-04$ & Hypothetical protein \\
\hline USA300HOU_RS05775 & & 2.62 & $2.08 \mathrm{E}-04$ & Hypothetical protein \\
\hline USA300HOU_RS05855 & & 2.80 & 1.39E-02 & Exotoxin \\
\hline USA300HOU_RS10450 & & 2.80 & $8.14 \mathrm{E}-04$ & Hypothetical protein \\
\hline USA300HOU_RS07070 & pstS & 2.85 & 5.80E-05 & Phosphate ABC superfamily ATP binding cassette transporter, binding protein \\
\hline USA300HOU_RS05795 & & 2.90 & 8.96E-05 & Fibrinogen-binding protein \\
\hline USA300HOU_RS01235 & hmp & 2.96 & $5.40 \mathrm{E}-05$ & Possible nitric oxide dioxygenase \\
\hline USA300HOU_RS10965 & $\operatorname{agrD}$ & 3.45 & $6.02 \mathrm{E}-04$ & Accessory gene regulator protein $D$ \\
\hline USA300HOU_RS04615 & & 4.03 & 5.89E-03 & Hypothetical protein \\
\hline USA300HOU_RS13630 & & 4.07 & $6.62 \mathrm{E}-06$ & ABC superfamily ATP binding cassette transporter, ABC protein \\
\hline USA300HOU_RS01365 & $\operatorname{lrg} B$ & 4.08 & $9.13 \mathrm{E}-08$ & Murein hydrolase regulator LrgB \\
\hline USA300HOU_RS01360 & $\operatorname{lrg} A$ & 4.36 & $1.25 \mathrm{E}-08$ & Murein hydrolase regulator LrgA \\
\hline USA300HOU_RS01230 & & 6.07 & 1.16E-06 & Hypothetical protein \\
\hline
\end{tabular}

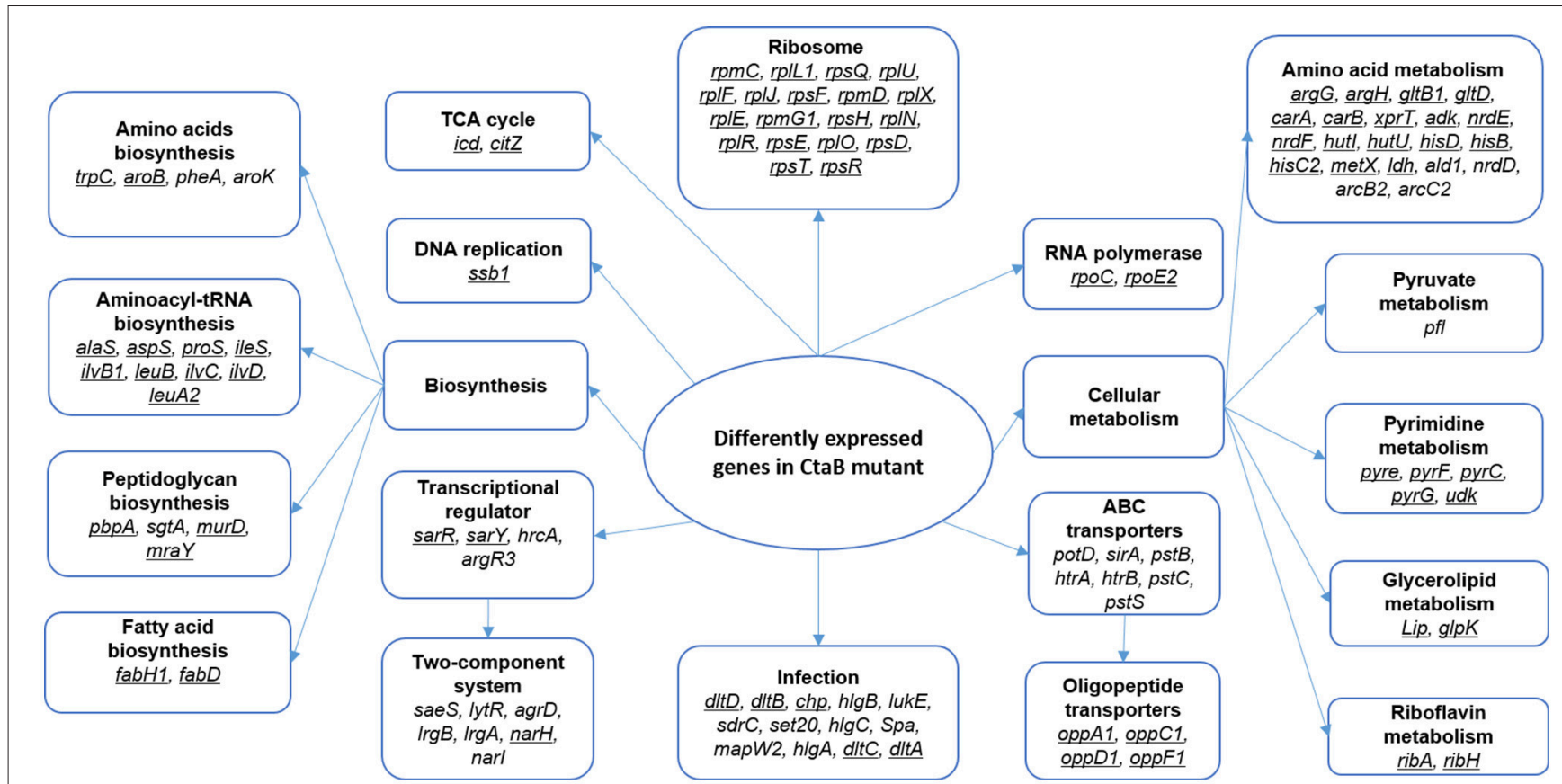

FIGURE 6 | Proposed pathways affected by depletion of CtaB in stationary phase S. aureus. Pathways enriched in genes with higher than 2-fold change in CtaB mutant at $24 \mathrm{~h}$ are framed and bold. Genes that were down regulated in the CtaB mutant are underlined, while those up regulated not underlined.

still attenuated virulence despite increased pigment production which is often associated with virulence.

Persister formation is a phenomenon with highly complex mechanisms. Energy production and protein translation are two vital pathways for bacterial survival and reproduction, and it is generally believed that an overall suppression of metabolism and replication is a universal cause for bacterial persister formation (Lewis, 2012; Kwan et al., 2013). In E. coli, deficiency of energy production genes such as $s u c B$ and $u b i F$ has been found to decrease persister survival (Ma et al., 2010). It has also been shown in $E$. coli that bacteriostatic antibiotic treatment enhances persister formation via suppression of 


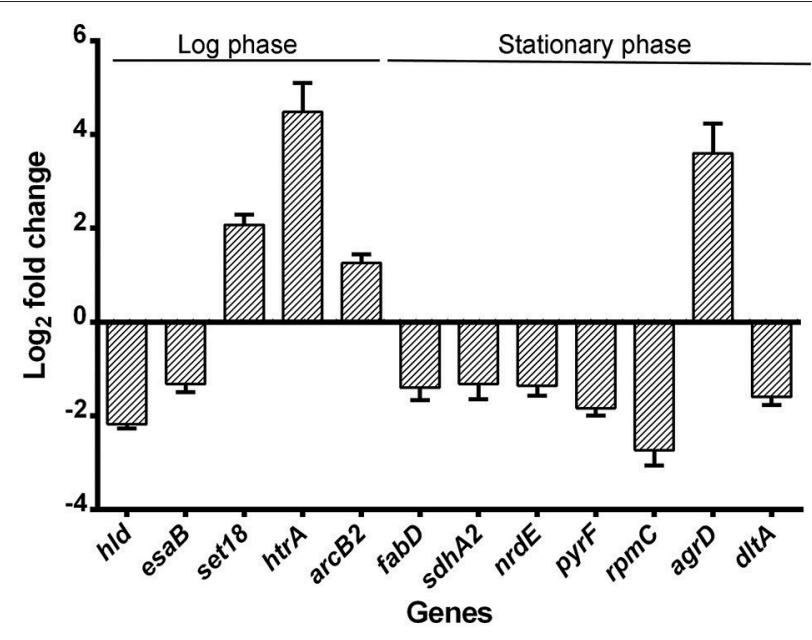

FIGURE 7 | Validation of RNA-seq by quantitative real-time PCR. Relative mRNA levels of transcripts corresponding to USA500 and $\triangle \mathrm{ctaB}$ mutant grown to 6 or $24 \mathrm{~h}$ were determined. RNA was obtained from the same samples for RNA-seq and experiments were performed in triplicate. Bars show the fold change of $\triangle$ ctaB mutant vs. USA500 and error bars indicate standard deviations calculated with the $2^{-\Delta \Delta C T}$ method based on three independent experiments.

TABLE 4 | Transcription change of pigment production associated genes.

\begin{tabular}{lcc}
\hline Genes & Fold change (ActaB vs. USA500) & SD \\
\hline rsbU & 0.90 & 0.122 \\
crtM & 1.18 & 0.143 \\
qoxB & 2.09 & 0.276 \\
citZ & 0.45 & 0.089 \\
fliA (sigB) & 0.91 & 0.129 \\
purA & 0.56 & 0.113 \\
USA300HOU_0726 (NWMN_0672) & 1.38 & 0.127 \\
USA30OHOU_(NWMN_1144) & 3.54 & 0.323 \\
\hline
\end{tabular}

cellular respiration (Lobritz et al., 2015). In S. aureus, a recent study correlated the drop of ATP level to enhanced persister formation in stationary phase (Pontes et al., 2015). $\mathrm{CtaB}$ is a key factor in $S$. aureus respiratory chain and energy production. In stationary phase when most glucose is consumed, $S$. aureus turns to utilize amino acids such as arginine and histidine for energy production (Makhlin et al., 2007). We also found that in stationary phase, multiple genes involved in amino acid metabolism ( $\arg G$, hutI, hisD, etc.) were inhibited in $\triangle c t a B$ strain (Table 3). Based on these findings, $\mathrm{CtaB}$ depletion might account for augumented persister formation. However, the correlation between respiration and persister formation is far from unveiled. A counter-example has been provided by Mehmet et al. who reported that inhibition of respiration during stationary phase with $\mathrm{KCN}$ reduced persister levels in E. coli (Orman and Brynildsen, 2015).

While more work needs to be done to investigate the role of respiratory chain in persister formation, it is also important to further investigate how repression of protein production affects persister formation. The well-understood mechanism of HipAB Toxin-antitoxin system affecting persister formation in E. coli, relies on (p)ppGpp to trigger a regulatory cascade involving inorganic polyphosphate (polyP) and Lon, which eventually results in accumulation of (p)ppGpp and persister formation (Rodionov and Ishiguro, 1995; Korch et al., 2003; Germain et al., 2013; Maisonneuve et al., 2013). In our study, CtaB depletion caused strong inhibition of translation by repressing genes involved in multiple aspects of protein production, including amino acid transport ( $o p p A 1, o p p C 1, o p p D 1$, etc.), amino acid synthesis (trpC, aroB,), aminoacyl-tRNA biosynthesis (aspS, alaS, ileS, etc.) and ribosome proteins $(r p m C, r p l F, r p s E$, etc.) (Table 3; Figure 6).

It is generally assumed that elevated persistence is associated with better survival and therefore higher virulence in animal models. However, our observation that mutation of CtaB caused attenuated virulence but elevated persister formation, seems paradoxical. Indeed, many infectious diseases are difficult to be treated with antibiotics due to persisters but not resistance (Mulcahy et al., 2010; Welsh et al., 2011). However, we propose that in most cases with MRSA infection the role of virulence is greater than persister formation because: the proportion of persisters is generally small; after antibiotics kill the majority of infecting population of bacteria, the host immune system generally eliminates persisters non-selectively. Nevertheless, the importance of persister formation by MRSA should not be neglected. Future studies are needed to better understand the roles virulence and persistence play in $S$. aureus infection.

In our study, the $\mathrm{CtaB}$ mutant only showed elevated persister formation with levofloxacin and ciprofloxacin but no other antibiotics. This may be attributed to the multi-drug resistance of the MRSA strain, which may have masked the defect in persistence to other antibiotics. The difference in persister formation between MRSA and methicillin-sensitive $S$. aureus (MSSA) is worth further investigation.

Our study suggests the importance of heme synthesis in virulence and persister formation of $S$. aureus and provide new insights into the role of $\mathrm{CtaB}$ in bacterial respiration in S. aureus virulence and persistence. However, one limitation of the study is that we have not dealt specifically with the metabolic aspects of $\mathrm{CtaB}$ mutation, such as the efficiency of the respiratory chain in the mutant and possible changes in components of the TCA cycle as well as comparing the phenotypes of $S$. aureus and the $c t a B$ mutant in anaerobic conditions. Future studies are needed to address these issues and better understand the relationship between $S$. aureus respiration and virulence and persistence.

\section{AUTHOR CONTRIBUTIONS}

$\mathrm{YZ}$, TX, and WZ designed the work and revised the manuscript; TX, JH, JZ, JC, and NW completed all the experiments; TX and $\mathrm{JH}$ performed the statistically analysis and made the figures; TX and $\mathrm{YZ}$ wrote the manuscript. 


\section{ACKNOWLEDGMENTS}

We thank Timothy J. Foster, Moyne Institute of Preventive Medicine, Department of Microbiology, Trinity College, Dublin, Ireland, for providing the E. coli strain DC10B. We also thank Ralph Bertram, Klinikum Nürnberg Medical School GmbH, Research Department, Paracelsus Medical

\section{REFERENCES}

Anderson, M., Chen, Y. H., Butler, E. K., and Missiakas, D. M. (2011). EsaD, a secretion factor for the Ess pathway in Staphylococcus aureus. J. Bacteriol. 193, 1583-1589. doi: 10.1128/JB.01096-10

Andrews, J. M. (2001). Determination of minimum inhibitory concentrations. J. Antimicrob. Chemother. 48(Suppl. 1), 5-16. doi: 10.1093/jac/48.suppl_1.5

Atshan, S. S., Shamsudin, M. N., Lung, L. T., Ling, K. H., Sekawi, Z., Pei, C. P., et al. (2012). Improved method for the isolation of RNA from bacteria refractory to disruption, including S. aureus producing biofilm. Gene 494, 219-224. doi: 10.1016/j.gene.2011.12.010

Bae, T., Banger, A. K., Wallace, A., Glass, E. M., Aslund, F., Schneewind, O., et al. (2004). Staphylococcus aureus virulence genes identified by bursa aurealis mutagenesis and nematode killing. Proc. Natl. Acad. Sci. U.S.A. 101, 12312-12317. doi: 10.1073/pnas.0404728101

Bae, T., and Schneewind, O. (2006). Allelic replacement in Staphylococcus aureus with inducible counter-selection. Plasmid 55, 58-63. doi: 10.1016/j.plasmid.2005.05.005

Bigger, J. (1944). Treatment of staphylococcal infections with penicillin by intermittent sterilisation. Lancet 244, 497-500. doi: 10.1016/S01406736(00)74210-3

Burts, M. L., DeDent, A. C., and Missiakas, D. M. (2008). EsaC substrate for the ESAT-6 secretion pathway and its role in persistent infections of Staphylococcus aureus. Mol. Microbiol. 69, 736-746. doi: 10.1111/j.1365-2958.2008. 06324. $\mathrm{x}$

Carrel, M., Perencevich, E. N., and David, M. Z. (2015). USA300 methicillinresistant Staphylococcus aureus, United States, 2000-2013. Emer. Infect. Dis. J. 21, 1973-1980. doi: 10.3201/eid2111.150452

Clauditz, A., Resch, A., Wieland, K. P., Peschel, A., and Götz, F. (2006). Staphyloxanthin plays a role in the fitness of Staphylococcus aureus and its ability to cope with oxidative stress. Infect. Immun. 74, 4950-4953. doi: 10.1128/IAI.00204-06

Clements, M. O., Watson, S. P., Poole, R. K., and Foster, S. J. (1999). CtaA of Staphylococcus aureus is required for starvation survival, recovery, and cytochrome biosynthesis. J. Bacteriol. 181, 501-507.

Collins, L. V., Kristian, S. A., Weidenmaier, C., Faigle, M., Van Kessel, K. P., Van Strijp, J. A., et al. (2002). Staphylococcus aureus strains lacking D-alanine modifications of teichoic acids are highly susceptible to human neutrophil killing and are virulence attenuated in mice. J. Infect. Dis. 186, 214-219. doi: $10.1086 / 341454$

Coulter, S. N., Schwan, W. R., Ng, E. Y., Langhorne, M. H., Ritchie, H. D., Westbrock-Wadman, S., et al. (1998). Staphylococcus aureus genetic loci impacting growth and survival in multiple infection environments. Mol. Microbiol. 30, 393-404.

Diep, B. A., Carleton, H. A., Chang, R. F., Sensabaugh, G. F., and PerdreauRemington, F. (2006). Roles of 34 virulence genes in the evolution of hospitaland community-associated strains of methicillin-resistant Staphylococcus aureus. J. Infect. Dis. 193, 1495-1503. doi: 10.1086/503777

Drabkin, D. L. (1951). Metabolism of the hemin chromoproteins. Physiol. Rev. 31, 345-431.

Germain, E., Castro-Roa, D., Zenkin, N., and Gerdes, K. (2013). Molecular mechanism of bacterial persistence by HipA. Mol. Cell 52, 248-254. doi: 10.1016/j.molcel.2013.08.045

Giachino, P., Engelmann, S., and Bischoff, M. (2001). Sigma(B) activity depends on RsbU in Staphylococcus aureus. J. Bacteriol. 183, 1843-1852. doi: 10.1128/JB.183.6.1843-1852.2001
University, Nuremberg, Germany for helpful discussions about S. aureus gene manipulation and persister assay. This work was supported by the National Natural Science Foundation of China (81572046 and 81471987), and the Key Technologies Research and Development Program for Infectious Diseases of China (2013ZX10003008-003). YZ was supported in part by NIH grants AI99512 and AI108535.
Hammer, N. D., Schurig-Briccio, L. A., Gerdes, S. Y., Gennis, R. B., and Skaar, E. P. (2016). CtaM is required for menaquinol oxidase $\mathrm{aa}_{3}$ function in Staphylococcus aureus. mBio 7:e00823-16. doi: 10.1128/mBio.00823-16

Han, J., He, L., Shi, W., Xu, X., Wang, S., Zhang, S., et al. (2014). Glycerol uptake is important for L-form formation and persistence in Staphylococcus aureus. PLoS ONE 9:e108325. doi: 10.1371/journal.pone.0108325

Hederstedt, L., Lewin, A., and Throne-Holst, M. (2005). Heme A synthase enzyme functions dissected by mutagenesis of Bacillus subtilis CtaA. J. Bacteriol. 187, 8361-8369. doi: 10.1128/JB.187.24.8361-8369.2005

Keren, I., Kaldalu, N., Spoering, A., Wang, Y., and Lewis, K. (2004). Persister cells and tolerance to antimicrobials. FEMS Microbiol. Lett. 230, 13-18. doi: 10.1016/S0378-1097(03)00856-5

Korch, S. B., Henderson, T. A., and Hill, T. M. (2003). Characterization of the hipA7 allele of Escherichia coli and evidence that high persistence is governed by (p)ppGpp synthesis. Mol. Microbiol. 50, 1199-1213. doi: 10.1046/j.13652958.2003.03779.x

Kullik, I., Giachino, P., and Fuchs, T. (1998). Deletion of the alternative sigma factor sigmaB in Staphylococcus aureus reveals its function as a global regulator of virulence genes. J. Bacteriol. 180, 4814-4820

Kwan, B. W., Valenta, J. A., Benedik, M. J., and Wood, T. K. (2013). Arrested protein synthesis increases persister-like cell formation. Antimicrob. Agents Chemother. 57, 1468-1473. doi: 10.1128/AAC.02135-12

Lan, L., Cheng, A., Dunman, P. M., Missiakas, D., and He, C. (2010). Golden pigment production and virulence gene expression are affected by metabolisms in Staphylococcus aureus. J. Bacteriol. 192, 3068-3077. doi: 10.1128/JB.00928-09

Lechner, S., Lewis, K., and Bertram, R. (2012). Staphylococcus aureus persisters tolerant to bactericidal antibiotics. J. Mol. Microbiol. Biotechnol. 22, 235-244. doi: $10.1159 / 000342449$

Lewis, K. (2001). Riddle of biofilm resistance. Antimicrob. Agents Chemother. 45, 999-1007. doi: 10.1128/AAC.45.4.999-1007.2001

Lewis, K. (2012). "Persister cells: molecular mechanisms related to antibiotic tolerance," in Antibiotic Resistance, ed A. R. M. Coate (Heidelberg: Springer), 121-133.

Li, M., Du, X., Villaruz, A. E., Diep, B. A., Wang, D., Song, Y., et al. (2012). MRSA epidemic linked to a quickly spreading colonization and virulence determinant. Nat. Med. 18, 816-819. doi: 10.1038/nm.2692

Liu, G. Y. (2009). Molecular pathogenesis of Staphylococcus aureus infection. Pediatr Res 65(5 Pt 2), 71R-77R. doi: 10.1203/PDR.0b013e31819dc44d

Liu, G. Y., Essex, A., Buchanan, J. T., Datta, V., Hoffman, H. M., Bastian, J. F., et al. (2005). Staphylococcus aureus golden pigment impairs neutrophil killing and promotes virulence through its antioxidant activity. J. Exp. Med. 202, 209-215. doi: $10.1084 /$ jem. 20050846

Liu, M., Tanaka, W. N., Zhu, H., Xie, G., Dooley, D. M., and Lei, B. (2008). Direct hemin transfer from IsdA to IsdC in the iron-regulated surface determinant (Isd) heme acquisition system of Staphylococcus aureus. J. Biol. Chem. 283, 6668-6676. doi: 10.1074/jbc.M708372200

Livak, K. J., and Schmittgen, T. D. (2001). Analysis of relative gene expression data using real-time quantitative PCR and the $2(-$ Delta Delta $\mathrm{C}(\mathrm{T}))$ method Methods 25, 402-408. doi: 10.1006/meth.2001.1262

Lobritz, M. A., Belenky, P., Porter, C. B., Gutierrez, A., Yang, J. H., Schwarz, E. G., et al. (2015). Antibiotic efficacy is linked to bacterial cellular respiration. Proc. Natl. Acad. Sci. U.S.A. 112, 8173-8180. doi: 10.1073/pnas.1509743112

Ma, C., Sim, S., Shi, W., Du, L., Xing, D., and Zhang, Y. (2010). Energy production genes sucB and ubiF are involved in persister survival and tolerance to multiple antibiotics and stresses in Escherichia coli. FEMS Microbiol. Lett. 303, 33-40. doi: 10.1111/j.1574-6968.2009.01857.x 
Maisonneuve, E., Castro-Camargo, M., and Gerdes, K. (2013). (p)ppGpp controls bacterial persistence by stochastic induction of toxin-antitoxin activity. Cell 154, 1140-1150. doi: 10.1016/j.cell.2013.07.048

Makhlin, J., Kofman, T., Borovok, I., Kohler, C., Engelmann, S., Cohen, G., et al. (2007). Staphylococcus aureus ArcR controls expression of the arginine deiminase operon. J. Bacteriol. 189, 5976-5986. doi: 10.1128/JB. 00592-07

Mason, W. J., and Skaar, E. P. (2009). Assessing the contribution of heme-iron acquisition to Staphylococcus aureus pneumonia using computed tomography. PLoS ONE 4:e6668. doi: 10.1371/journal.pone.00 06668

Mazmanian, S. K., Skaar, E. P., Gaspar, A. H., Humayun, M., Gornicki, P., Jelenska, J., et al. (2003). Passage of heme-iron across the envelope of Staphylococcus aureus. Science 299, 906-909. doi: 10.1126/science.10 81147

Mechler, L., Herbig, A., Paprotka, K., Fraunholz, M., Nieselt, K., and Bertram, R. (2015). A novel point mutation promotes growth phase-dependent daptomycin tolerance in Staphylococcus aureus. Antimicrob. Agents Chemother. 59, 5366-5376. doi: 10.1128/AAC.00643-15

Mei, J. M., Nourbakhsh, F., Ford, C. W., and Holden, D. W. (1997). Identification of Staphylococcus aureus virulence genes in a murine model of bacteraemia using signature-tagged mutagenesis. Mol. Microbiol. 26, 399-407.

Mogi, T., Saiki, K., and Anraku, Y. (1994). Biosynthesis and functional role of haem $\mathrm{O}$ and haem A. Mol. Microbiol. 14, 391-398. doi: 10.1111/j.13652958.1994.tb02174.x

Monk, I. R., Shah, I. M., Xu, M., Tan, M. W., and Foster, T. J. (2012). Transforming the untransformable: application of direct transformation to manipulate genetically Staphylococcus aureus and Staphylococcus epidermidis. MBio 3:e00277-11. doi: 10.1128/mBio.00277-11

Morikawa, K., Maruyama, A., Inose, Y., Higashide, M., Hayashi, H., and Ohta, T. (2001). Overexpression of Sigma Factor, $\zeta$ B, urges Staphylococcus aureus to thicken the cell wall and to resist $\beta$-Lactams. Biochem. Biophys. Res. Commun. 288, 385-389. doi: 10.1006/bbrc.2001.5774

Mulcahy, L. R., Burns, J. L., Lory, S., and Lewis, K. (2010). Emergence of Pseudomonas aeruginosa strains producing high levels of persister cells in patients with cystic fibrosis. J. Bacteriol. 192, 6191-6199. doi: 10.1128/JB. 01651-09

Orman, M. A., and Brynildsen, M. P. (2015). Inhibition of stationary phase respiration impairs persister formation in E. coli. Nat. Commun. 6:7983. doi: $10.1038 /$ ncomms8983

Pelz, A., Wieland, K. P., Putzbach, K., Hentschel, P., Albert, K., and Götz, F. (2005). Structure and biosynthesis of staphyloxanthin from Staphylococcus aureus. J. Biol. Chem. 280, 32493-32498. doi: 10.1074/jbc.M5050 70200

Peschel, A., Otto, M., Jack, R. W., Kalbacher, H., Jung, G., and Götz, F. (1999). Inactivation of the dlt operon in Staphylococcus aureus confers sensitivity to defensins, protegrins, and other antimicrobial peptides. J. Biol. Chem. 274, 8405-8410.

Podbielski, A., Pohl, B., Woischnik, M., Körner, C., Schmidt, K. H., Rozdzinski, E., et al. (1996). Molecular characterization of group A streptococcal (GAS) oligopeptide permease (opp) and its effect on cysteine protease production. Mol. Microbiol. 21, 1087-1099.
Pontes, M. H., Sevostyanova, A., and Groisman, E. A. (2015). When too much ATP is bad for protein synthesis. J. Mol. Biol. 427, 2586-2594. doi: 10.1016/j.jmb.2015.06.021

Reichmann, N. T., Cassona, C. P., and Gründling, A. (2013). Revised mechanism of D-alanine incorporation into cell wall polymers in Gram-positive bacteria. Microbiology 159(Pt 9), 1868-1877. doi: 10.1099/mic.0.069898-0

Resch, A., Leicht, S., Saric, M., Pásztor, L., Jakob, A., Götz, F., et al. (2006). Comparative proteome analysis of Staphylococcus aureus biofilm and planktonic cells and correlation with transcriptome profiling. Proteomics 6, 1867-1877. doi: 10.1002/pmic.200500531

Rodionov, D. G., and Ishiguro, E. E. (1995). Direct correlation between overproduction of guanosine $3^{\prime}, 5^{\prime}$-bispyrophosphate (ppGpp) and penicillin tolerance in Escherichia coli. J. Bacteriol. 177, 4224-4229.

Svensson, B., and Hederstedt, L. (1994). Bacillus subtilis CtaA is a hemecontaining membrane protein involved in heme A biosynthesis. J. Bacteriol. $176,6663-6671$.

Svensson, B., Lübben, M., and Hederstedt, L. (1993). Bacillus subtilis CtaA and CtaB function in haem A biosynthesis. Mol. Microbiol. 10, 193-201. doi: 10.1111/j.1365-2958.1993.tb00915.x

Szkopinska, A., and Plochocka, D. (2005). Farnesyl diphosphate synthase; regulation of product specificity. Acta Biochim. Pol. 52, 45-55. doi: 055201045

Wang, B., and Muir, T. W. (2016). Regulation of virulence in Staphylococcus aureus: molecular mechanisms and remaining puzzles. Cell Chem. Biol. 23, 214-224. doi: 10.1016/j.chembiol.2016.01.004

Wang, W., Chen, J., Chen, G., Du, X., Cui, P., Wu, J., et al. (2015). Transposon mutagenesis identifies novel genes associated with Staphylococcus aureus persister formation. Front. Microbiol. 6:1437. doi: 10.3389/fmicb.2015.01437

Welsh, K. J., Skrobarcek, K. A., Abbott, A. N., Lewis, C. T., Kruzel, M. C., Lewis, E. M., et al. (2011). Predictors of relapse of methicillin-resistant Staphylococcus aureus bacteremia after treatment with vancomycin. J. Clin. Microbiol. 49, 3669-3672. doi: 10.1128/JCM.05287-11

Wieland, B., Feil, C., Gloria-Maercker, E., Thumm, G., Lechner, M., Bravo, J. M., et al. (1994). Genetic and biochemical analyses of the biosynthesis of the yellow carotenoid 4,4'-diaponeurosporene of Staphylococcus aureus. J. Bacteriol. 176, 7719-7726

Yee, R., Cui, P., Shi, W., Feng, J., and Zhang, Y. (2015). Genetic screen reveals the role of purine metabolism in Staphylococcus aureus persistence to rifampicin. Antibiotics 4, 627-642. doi: 10.3390/antibiotics4040627

Zhang, Y. (2014). Persisters, persistent infections and the Yin-Yang model. Emerg. Microbes Infect. 3:e3. doi: 10.1038/emi.2014.3

Conflict of Interest Statement: The authors declare that the research was conducted in the absence of any commercial or financial relationships that could be construed as a potential conflict of interest.

Copyright (C) 2016 Xu, Han, Zhang, Chen, Wu, Zhang and Zhang. This is an openaccess article distributed under the terms of the Creative Commons Attribution License (CC BY). The use, distribution or reproduction in other forums is permitted, provided the original author(s) or licensor are credited and that the original publication in this journal is cited, in accordance with accepted academic practice. No use, distribution or reproduction is permitted which does not comply with these terms. 